\title{
PENJADWALAN JOB SHOP STATIK DENGAN METODE SIMULATED ANNEALING UNTUK MEMINIMASI WAKTU MAKESPAN
}

\author{
Moh.Husen, Ilyas Masudin, Dana Marsetiya Utama \\ Jurusan Teknik Industri - Universitas Muhammadiyah Malang \\ Muhammad.husen12@yahoo.com
}

\begin{abstract}
ABSTRAK
Penjadwalan bagi perusahaan adalah aspek yang sangat penting, karena penjadwalan merupakan salah satu elemen perencanaan dan pengendalian produksi, sehingga perusahaan dapat mengirim barang sesuai dengan waktu yang telah ditentukan, agar diperoleh waktu total penyelesaian yang minimum. Dalam penelitian ini, penjadwalan menggunakan metode Simulated Annealing (SA) dengan bantuan Matlab diharapkan dapat menghasilkan waktu total penyelesaian (makespan) lebih cepat dari penjadwalan yang ada pada perusahaan. Metode SA mensimulasikan proses annealing pada pembuatan materi yang terdiri dari butiran Kristal atau logam. Tujuan dari proses ini adalah menghasilkan struktur kristal yang baik dengan menggunakan energi seminimal mungkin. Permasalahan yang dihadapi oleh perusahaan adalah perusahaan belum mempertimbangkan makespan dalam penyelesaian produk dan penjadwalan produksi untuk produk paket satu rumah kos-kosan. Hal ini berdasarkan data produksi yang terjadi keterlambatan dilihat dari waktu penyelesaian (makespan) produksi, sehingga perusahaan harus menambah 2-5 hari lagi untuk bisa menyelesaikan keseluruhan produk. Dengan menggunakan metode SA menghasilkan makespan 23 jam, lebih cepat 2 jam dari pada penjadwalan awal.
\end{abstract}

Kata kunci : penjadwalan, job shop, simulated annealing, idle time, makespan.

\section{PENDAHULUAN}

Proses penjadwalan adalah proses yang penting dalam dunia industri khususnya dalam bidang produksi. Penjadwalan yang tepat sangat penting bagi perusahaan agar bisa meminimalkan waktu penyelesaian (makespan) produksi, sehingga perusahaan dapat mengirimkan barang sesuai dengan waktu, agar diperoleh waktu total penyelesaian yang minimum. Menurut Ginting (2009), penjadwalan adalah pengalokasian sumber daya yang terbatas untuk mengerjakan sebuah pekerjaan. Bagaimana mengalokasikan sumber daya yang terbatas untuk menentukan suatu prioritas pekerjaan dalam suatu rangkaian kegiatan dalam jangka waktu tertentu agar diperoleh waktu total penyelesaian pekerjaan yang minimum.

Penjadwalan produksi yang dilakukan oleh perusahaan dimulai dari mengerjakan produk, yaitu dimulai dari Kusen pintu kamar mandi, daun jendela, daun pintu kamar, kusen jendela, daun pintu utama, kusen pintu utama, daun Pintu kamar mandi.

Permasalahan yang dihadapi oleh perusahaan adalah perusahaan belum mempertimbangkan makespan dalam penyelesaian produk dan penjadwalan produksi untuk produk paket satu rumah kos-kosan. Hal ini berdasarkan data produksi pada bulan Desember 2013 dan Agustus 2014 yang terjadi keterlambatan dilihat dari waktu penyelesaian produksi, sehingga perusahaan harus menambah 2-5 hari lagi untuk bisa menyelesaikan keseluruhan produk yang dipesan oleh pelanggan.

Berdasarkan pada permasalahan diatas, perlu dilakukan suatu Penjadwalan agar bisa meminimalkan waktu penyelesaian produksi, sehingga perusahaan dapat mengirimkan barang sesuai dengan waktu yang ditentukan, agar diperoleh waktu total penyelesaian yang minimum. Pada penelitian ini, penjadwalan menggunakan metode simulated annealing (SA), sedangkan teknik pengacakannya menggunakan metode swap (menukar), flip (membalik), dan slide (menggeser). Dengan menggunakan bantuan software matlab diharapkan bisa menyelesaikan permasalahan yang dialami perusahaan lebih cepat dan akurat. 


\section{LANDASAN TEORI}

\section{A. PENJADWALAN}

Yang dimaksud dengan Penjadwalan adalah pengurutan pembuatan/pengerjaan produk secara menyeluruh yang dikerjakan pada beberapa buah mesin. Dengan demikian masalah sequencing senantiasa melibatkan pengerjaan sejumlah komponen yang sering disebut dengan istilah ' $j o b$ '. Job sendiri masih merupakan komposisi dari sejumlah elemen-elemen dasar yang disebut aktivitas atau operasi ini membutuhkan alokasi sumber daya tertentu selama periode waktu tertentu yang sering disebut dengan waktu proses (Ginting, 2009).

Persoalan penjadwalan dapat diklasifikasikan berdasarkan faktor-faktor yaitu:

1. Penjadwalan pada mesin tunggal

Penjadwalan mesin tunggal merupakan salah satu model pengurutan pekerjaan dimana pekerjaan yang hendak diurutkan sedang menunggu untuk diproses pada sebuah mesin tunggal.

2. Penjadwalan pada $m$ mesin

Penjadwalan pada $m$ mesin (mesin jamak) merupakan pengurutan serangkaian pekerjaan yang hendak diproses pada beberapa mesin baik seri, parallel, maupun kombinasinya.

3. Statik

Semua pekerjaan datang secara bersamaan dan semua fasilitas tersedia pada saat kedatangan pekerjaan.

4. Dinamik

Pekerjaan datang secara acak selama masa penjadwalan.

5. Deterministik

Terdapat kapasitas tentang pekerjaan dan mesin, misalnya tentang waktu kadatangan, waktu setup, dan waktu proses.

6. Stokastik

Terdapat ketidakpastian mengenai pekerjaan dan mesin.

7. Flow shop

Pada pola aliran proses flow shop, semua job cenderung memiliki urutan operasi (routing) yang sama.

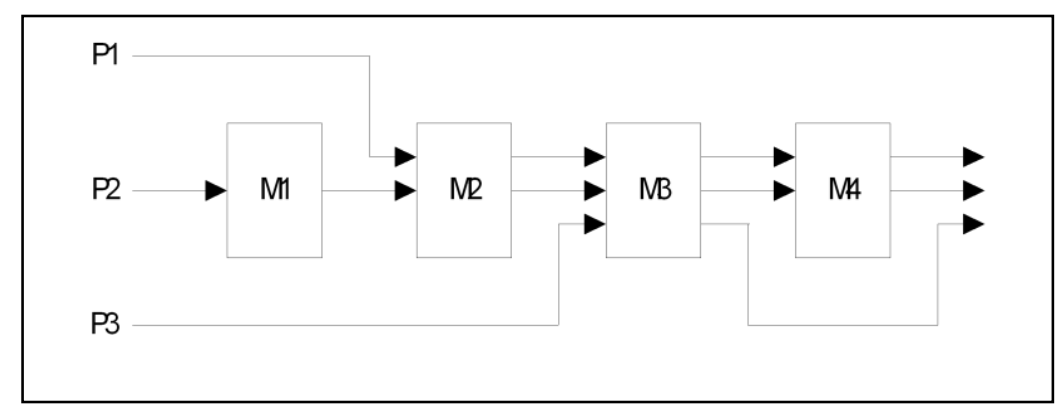

Gambar 1. Lintasan proses flow shop

8. Job Shop

Pada pola aliran proses job shop, masing-masing pekerjaan memiliki urutan operasi yang unik. Setiap pekerjaan bergerak dari satu mesin / stasiun kerja menuju mesin /stasiun kerja yang lain dengan pola yang berbeda-beda. 


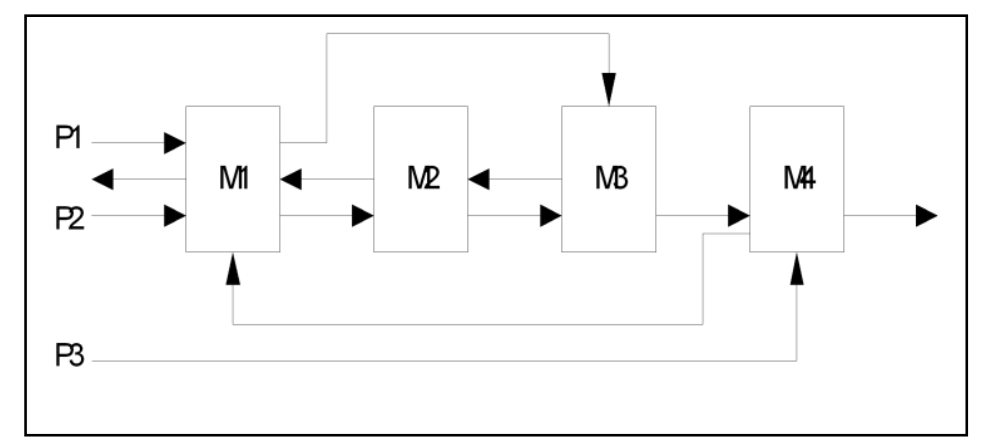

Gambar 2. Lintasan proses job shop

\section{B. SIMULATED ANNEALING (SA)}

Simulated Annealing (SA) mensimulasikan proses annealing pada pembuatan materi yang terdiri dari butir kristal (glassy) atau logam. Tujuan dari proses ini adalah menghasilkan struktur kristal yang baik dengan menggunakan energi seminimal mungkin. Jika kita memanaskan suatu materi keras hingga mencair dan kemudian mendinginkannya, maka sifat struktur dari materi tersebut bergantung pada tingkat pendinginan. Jika materi cair didinginkan secara berlahan, maka akan dihasilkan kristalkristal yang terbentuk tidak akan sempurna. Algoritma yang diusulkan Metropolis mensimulasikan materi sebagai suatu sistem dari partikel-partikel. Algoritma tersebut mensimulasikan proses pendinginan yang secara bertahap menurunkan suhu sistem hingga konvergen pada keadaan beku dan stabil (Suyanto, 2010).

\section{ALGORITMA SIMULATED ANNEALING (SA)}

Algoritma Simulated Annealing dimulai dengan suatu vektor solusi $\mathrm{x}_{1}$ (iterasi $\mathrm{i}=1$ ) dan nilai temperature $\mathrm{T}$ yang cukup tinggi. Bangkitkan vector solusi baru secara random yang dekat dari titik sekarang dan hitung perbedaan nilai fungsi tujuannya :

$$
\Delta E=\mathrm{E}_{\mathrm{i}+1}-\mathrm{E}_{\mathrm{i}}=\Delta f=\mathrm{f}_{\mathrm{i}+1}-\mathrm{f}_{\mathrm{i}}=\mathrm{f}\left(\mathrm{x}_{\mathrm{i}+1}\right)-\mathrm{f}\left(\mathrm{x}_{\mathrm{i}}\right)
$$

Jika $\mathrm{f}_{\mathrm{i}+1}$ lebih kecil dari $\mathrm{f}_{\mathrm{i}}$ (dengan nilai $\Delta f$ negatif), terima titik $\mathrm{f}_{\mathrm{i}+1}$ sebagai titik solusi baru. Sebaliknya, jika nilai $\Delta f$ positif, probabilitas menerima $\mathrm{x}_{\mathrm{i}+1}$ sebagai solusi baru adalah $e^{-\Delta f / k T}$. Untuk meneria atau tidak, perlu dicari pembanding terhadap nilai probabilitas ini. Kita perlu membangkitkan bilangan random antara (0.1).

Berikut Langkah-langkah Simulate Annealing $(S A)$ :

Pada penelitian Damanik (2011), Penjadwalan dengan metode simulated annealing memiliki langkah-langkah sebagai berikut:

1. Menentukan solusi awal penjadwalan

Pada tahap ini dilakukan perhitungan makespan sesuai dengan penjadwalan order yang ada di perusahaan pada keadaan aktual. Tahap ini penting dilakukan untuk mengetahui total waktu penyelesaiaan seluruh job order yang datang.

2. Menentukan temperatur awal (T0)

Sebelum melakukan pencarian solusi baru terlebih dahulu ditentukan temperatur awal. Temperatur awal ini cukup besar tujuannya adalah untuk mendapatkan ruang solusi yang lebih besar pada tahap awal pencarian solusi.

Pada algoritma Simulated Annealing, sekumpulan parameter harus didefenisikan terlebih dahulu diawal proses. Pendefenisian parameter-parameter ini disebut cooling schedule, yang melibatkan:

a. Nilai awal untuk parameter kontrol atau temperatur awal (TO)

b. Fungsi/faktor penurunan nilai parameter kontrol $(F)$

Nilai ini menentukan seberapa cepat parameter kontrol mengalami penurunan.

c. Jumlah iterasi dalam tiap nilai parameter $\operatorname{kontrol}(L)$

d. Kriteria terminasi untuk menghentikan eksekusi. 
Kriteria steady state proses pencarian dalam algoritma $S A$ dapat berupa dicapainya suatu jumlah iterasi tertentu di mana selama itu tidak ada solusi baru yang diterima, atau dicapainya nilai parameter kontrol tertentu yang telah ditetapkan sebelumnya.

e. Menentukan kondisi baru dengan melakukan iterasi. Iterasi dilakukan dengan menukar urutan job yang akan dikerjakan.

f. Mengevaluasi solusi baru yang layak diterima.

Jika solusi baru (S') lebih baik dari solusi sebelumnya (S), maka solusi baru dijadikan menjadi solusi sekarang. Jika tidak, dibangkitkan bilangan random (r) $[0,1]$ yang dibandingkan dengan probabilitas penerimaan $\mathrm{p}^{\prime}=\exp (-\Delta \mathrm{S} / \mathrm{T})$. Apabila $r<p$ ' maka solusi baru diterima sebagai solusi sekarang, dan apabila $r>p$ ' solusi baru ditolak .

g. Menentukan solusi penjadwalan yang terbaik.

Penentuan solusi terbaik dilakukan setelah algoritma dihentikan atau sudah berada dalam kondisi steady state. Menurut Syresh dan Sahu (1993) menggunakan kriteria penghentian, yaitu bila sudah ada tiga temperatur berturutturut sama, berarti sudah tidak ada lagi transisi yang diterima, atau tidak ada perbaikan nilai fingsi objektif, maka algoritma dihentikan. Jadi algoritma berhenti apabila dalam 3 kali penurunan suhu sudah tidak ada solusi yang lebih baik dari solusi sebelumnya yang diterima sesuai dengan solusi objektif. Dalam kondisi ini, algoritma dihentikan dan solusi yang telah ditemukan sudah optimal.

\section{METODELOGI PENELITIAN}

Algoritma ini didasarkan pada penelitian yang dilakukan oleh Damanik (2011) dan Firdaus (2014). Langkah-langkah dalam algoritma Simulated Annealing (SA) adalah 1) Memasukkan data waktu proses produksi sesuai dengan urutan prosesnya dan memasukkan parameter-parameter lain seperti suhu awal (T) 100, 200, 500,1000, dan faktor penurunan suhu (fp) 0.2, 0.5, 09. 2) Menghitung makespan dari urutan job awal. 3) Tetapkan iterasi pertama $=1$ dan siklus pertama $=1$. Buat urutan job acak dengan cara membangkitkan 2 bilangan random untuk urutan mana saja yang nanti akan dirubah. 4) Bangkitkan 1 bilangan random untuk penggunaan kriteria pengacakan. 5) Jika bilangan random $\leq 0.333$ maka akan dilakukan pengacakan urutan job dengan aturan flip. 6) Jika bilangan random $<0.333$ dan bilangan random $<0.667$ maka akan dilakukan pengacakan urutan job dengan aturan swap. 7) Jika bilangan random $\geq 0.667$ maka akan dilakukan pengacakan urutan job dengan aturan slide. 8) Menghitung makespan baru dari pengacakan urutan job diatas. 9) Menghitung selisih makespan awal dengan makespan baru. 10) Jika hasil selisih makespan negatif maka terima solusi baru dan solusi baru = solusi awal untuk iterasi selanjutnya jika tidak gunakan kriteria metropolis untuk menguji solusi baru jika diterima maka terima solusi baru dan jika tidak maka tetap menggunakan solusi awal. 11) Update iterasi $\mathrm{i}=\mathrm{i}+1$. 12) Update siklus $\mathrm{p}=\mathrm{p}+1$. 13) Jika $\mathrm{p} \geq 5$ maka lanjut ke proses berikutnya dan jika tidak kembali ke langkah "d". 14) Update iterasi dan siklus $\mathrm{p}=0.5$ ) Kurangi temperatur dengan temperatur yang sudah dikalikan dengan faktor penurunan suhu. 15) Jika kriteria sudah tercapai yaitu jika T sudah mencapai 0.0000001 yang artinya sudah tidak ada solusi baru yang bisa diterima maka solusi sudah beku dan keluar total makespan beserta urutan jobnya juga waktu komputasi yang dibutuhkan untuk melakukan running program matlab.

\section{HASIL DAN PEMBAHASAN}

\section{A. Penjadwalan Awal Perusahaan}

Pada penelitian ini solusi awal ditentukan menggunakan aturan FCFS. Penjadwalan dengan pendekatan FCFS ini diterapkan pada perusahaan dengan mengurutkan pekerjaan dari yang pertama datang. Dengan menggunakan metode FCFS maka didapat urutan schedule -nya: 


\begin{abstract}
$O_{111}, O_{122}, O_{133}, O_{144}, O_{155}, O_{212}, O_{221}, O_{234}, O_{245}, O_{253}, O_{313}, O_{322}, O_{334}, O_{341}, O_{515}$ $O_{355}, O_{414}, O_{425}, O_{433}, O_{442}, O_{451}, O_{524}, O_{532}, O_{541}, O_{553}, O_{611}, O_{623}, O_{634}, O_{645}, O_{652}$ $O_{712}, O_{723}, O_{735}, O_{744}, O_{751}$, sama dengan hasil running dalam MATLAB yaitu : 1 - 2 - 3 - 4 - 5 - $6-7-8-9-10-11-12-13-14-15-16-17-18$ $19-20-21-22-23-24-25-26-27-28-29-30-31-32-33-34$ - 35 , artinya $O_{111}$ (pekerjaan 1 operasi 1 dikerjakan pertama di mesin 1) sama dengan operasi ke 1 (berdasarkan hasil running MATLAB) dst.

Berdasarkan urutan schedule tersebut, kemudian dilakukan perhitungan makespan dengan bantuan komputasi matlab yang didapat sebesar 1506 menit. Berikut gambar gant chart hasil Penjadwalan dengan metode FCFS.
\end{abstract}

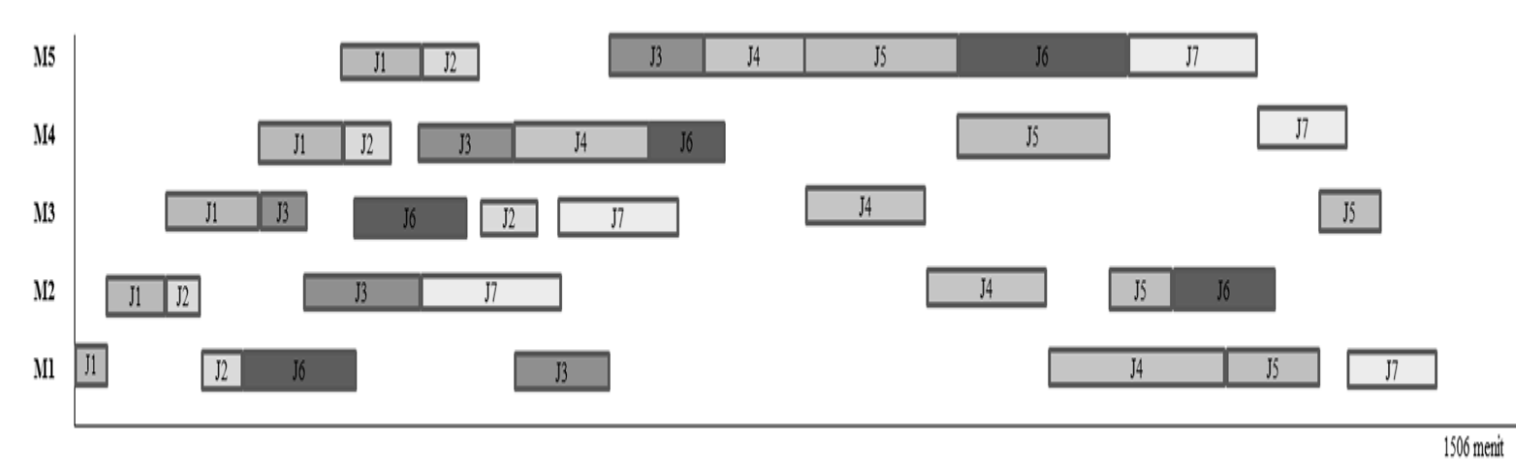

Gambar 3. Gambar Gantt Chart Penjadwalan awal dengan aturan FCFS

Keterangan :

\begin{tabular}{|l|l}
\hline J1 & Kusen pintu utama \\
\hline J2 & Kusen jendela \\
\hline J3 & Daun jendela \\
\hline J4 & Daun pintu kamar \\
J5 & Daun pintu utama \\
\hline J6 & Daun Pintu kamar mandi \\
\hline J7 & Kusen pintu kamar mandi \\
\hline
\end{tabular}

$\begin{array}{ll}\text { M1 } & \text { Mesin potong } \\ \text { M2 } & \text { Mesin Grinda } \\ \text { M3 } & \text { Mesin Strupil } \\ \text { M4 } & \text { Mesin Amplas } \\ \text { M5 } & \text { Mesin Bor }\end{array}$

Hasil penjadwalan produksi dengan metode FCFS pada perusahaan didapat makespan sebesar 1506 menit. Pada penjadwalan dengan metode ini masih dirasa kurang optimal, karena masih ada beberapa kemungkinan pengacakan dari job tersebut yang makespan nya lebih baik. Mengingat urutan dari setiap produk yang dijadikan sebagi job bisa ditukar.

\title{
B. Penjadwalan dengan Metode Simulated Annealing (SA)
}

Solusi awal yang digunakan dalam SA ini menggunakan aturan SPT (Shortest Processing Time). Prioritas tertinggi diberikan pada operasi dengan waktu proses terpendek.Pekerjaan dengan waktu proses terpendek akan diproses terlebih dahulu, kemudian berlanjut untuk job yang waktu prosesnya terpendek kedua dan seterusnya. Dari data perusahaan diperoleh data yang sudah diurutkan dengan aturan SPT yaitu : $O_{112}, O_{121}, O_{135}, O_{142}, O_{154}, O_{213}, O_{225}, O_{231}, O_{244}, O_{253}, O_{312}, O_{325}, O_{333}, O_{341}, O_{354}$, $O_{412}, O_{425}, O_{431}, O_{443} O_{454}, O_{513}, O_{522}, O_{531}, O_{541}, O_{554}, O_{612}, O_{621}, O_{635}, O_{645}, O_{655}$, $O_{714}, O_{724}, O_{733}, O_{742}, O_{753}$. sama dengan hasil running MATLAB yaitu : $6-7-9-$ 
$11-8-10-13-1-4-2-3-5-12-23-16-30-15-18-34-14-27-24-$ $26-35-19-20-33-29-21-22-28-32-31-17-25$, artinya $O_{212}$ (pekerjaan 2 operasi 1 dikerjakan pertama di mesin 2) sama dengan operasi ke 6 (berdasarkan hasil running MATLAB) dst. Berikut gambar gant chart hasil Penjadwalan dengan metode SA.

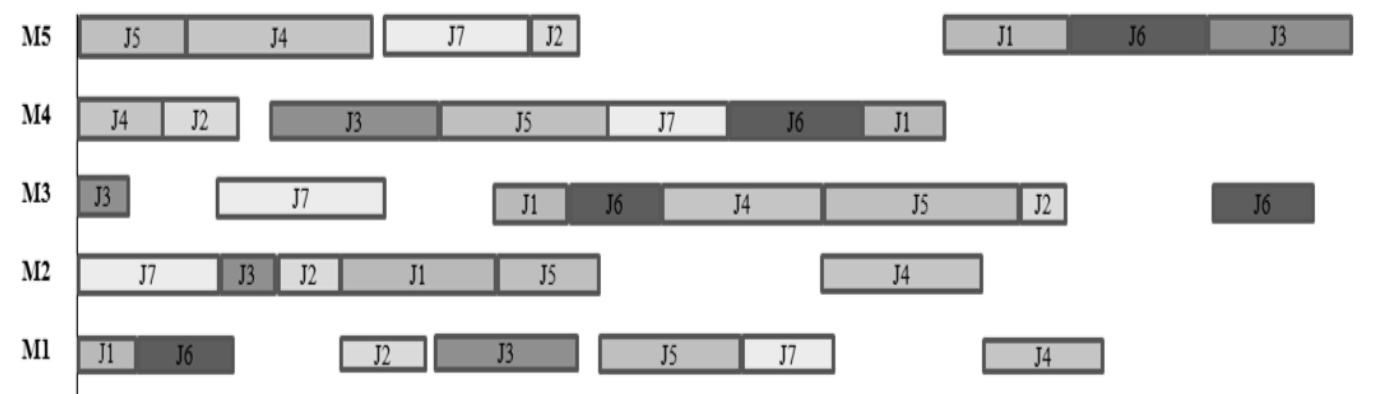

Gambar 4. Gambar Gantt Chart Penjadwalan awal dengan SA

Keterangan :

\begin{tabular}{|llll}
\hline J1 & Kusen pintu utama & M1 & Mesin potong \\
\hline J2 & Kusen jendela & M2 & Mesin Grinda \\
\hline J3 & Daun jendela & M3 & Mesin Strupil \\
J4 & Daun pintu kamar & M4 & Mesin Amplas \\
J5 & Daun pintu utama & M5 & Mesin Bor \\
\hline J6 & Daun Pintu kamar mandi & & \\
\hline J7 & Kusen pintu kamar mandi & & \\
\hline
\end{tabular}

Dari berbagai uji coba parameter $\mathrm{T}$ yang dilakukan didapat makespan paling baik sebesar 1391 menit yang dihasilkan oleh T $1000 \mathrm{fp}$ 0.5. Jadi solusi terbaik pada parameter $\mathrm{T} 1000$ dan fp 0.5 dengan operasi :

$O_{712}, O_{723}, O_{313}, O_{322}, O_{414}, O_{212}, O_{515}, O_{334}, O_{111}, O_{341}, O_{611}, O_{122}, O_{133}, O_{425}$, $O_{524}, O_{735}, O_{744}, O_{623}, O_{433}, O_{532}, O_{634}, O_{144}, O_{221}, O_{155}, O_{541}, O_{751}, O_{645}, O_{234}$,

$O_{442}, O_{553}, O_{355}, O_{245}, O_{652}, O_{451}, O_{253}$, sama dengan hasil dalam MATLAB yaitu : 31 $32-11-12 \quad 16-6-21-13 \quad 1-14-26-2 \quad 3-17-22-33 \quad 34-$ $27-18-2328-4-7-5 \quad 24-35-29-8 \quad 19-25-15-9 \quad 30-$ 20 - 10, artinya $O_{712}$ (pekerjaan 7 pada operasi 1 dikerjakan di mesin 2) sama dengan operasi ke 1 (berdasarkan hasil running MATLAB) dst, karena hanya menghasilkan 121 iterasi, dan waktu komputasi 0.0468 detik dan rata - rata waktu penyelesaian (mean flow time) sebesar : 1.080 .

\section{ANALISA SENSITIVITAS}

Dalam penelitihan ini parameter-parameter yang digunakan adalah parameter suhu (T) dan parameter faktor pereduksi suhu (fp). Berikut grafik perbandingan T 100, T 200, T 500, dan T 1000. Dimana pada setiap suhu (T) digunakan faktor penurunan suhu (fp) $0.2,0.5$, dan 0.9 yang nantinya parameter-parameter ini akan dilihat seberaba besar perubahannya dengan makespan, jumlah iterasi, mean flow time dan waktu komputasi. 


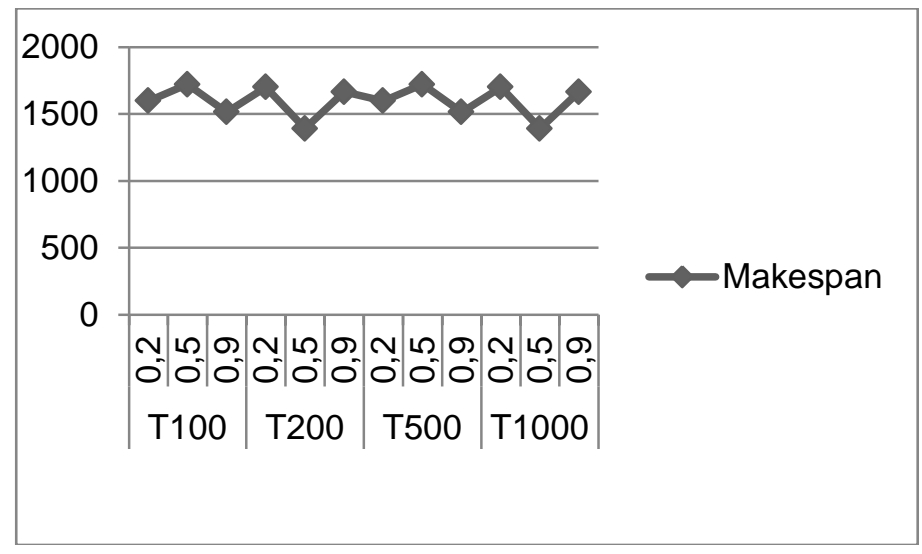

Gambar 6. Grafik Perbandingan nilai T dan makespan

Jika suhu rendah dan digunakan fp rendah juga, maka hasil dari makespan juga tinggi karena banyak titik optimal yang terlewati, jika suhu tinggi digunakan fp rendah juga masih belum bisa menemukan titik yang paling optimal. Sedangkan jika menggunakan T 0.5 suhu yang diturunkan tidak terlalu besar juga tidak terlalu tinggi, menghasilkan makespan yang lebih kecil karena pencarian solusi lebih banyak lagi. Dan untuk penggunaan fp tinggi yang berpengaruh hanya pada yang cukup tinggi pula yaitu pada T 500 dan 1000. Hal ini juga dipengaruhi oleh bilangan random yang dibangkitkan ketika pencarian solusi baru.

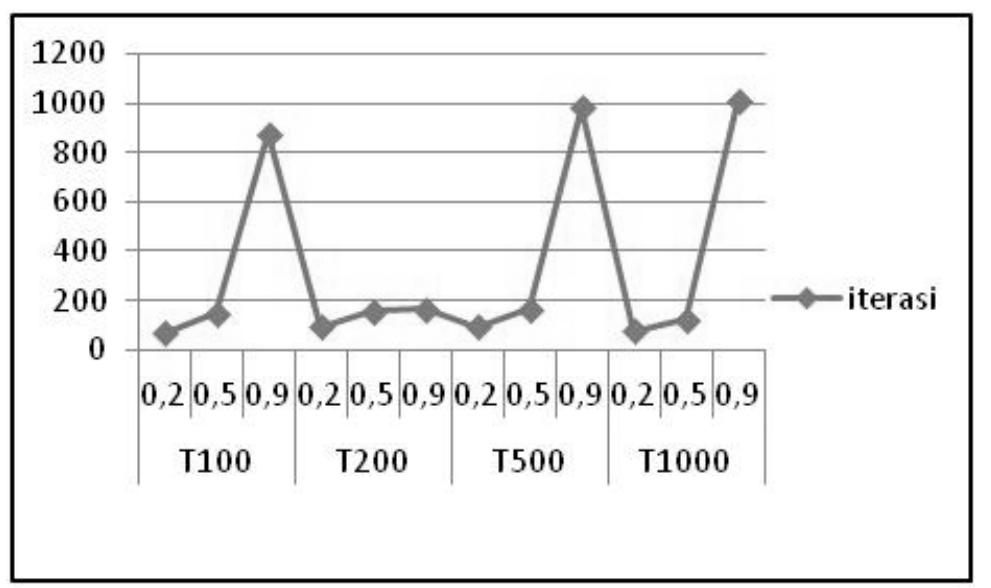

Gambar 7. Grafik Perbandingan T dan Jumlah Iterasi

Dari gambar diatas dapat dilihat setiap T yang dinaikkan dan fp yang dinaikkan, maka jumlah iterasi yang dihasilkan juga semakin banyak. 


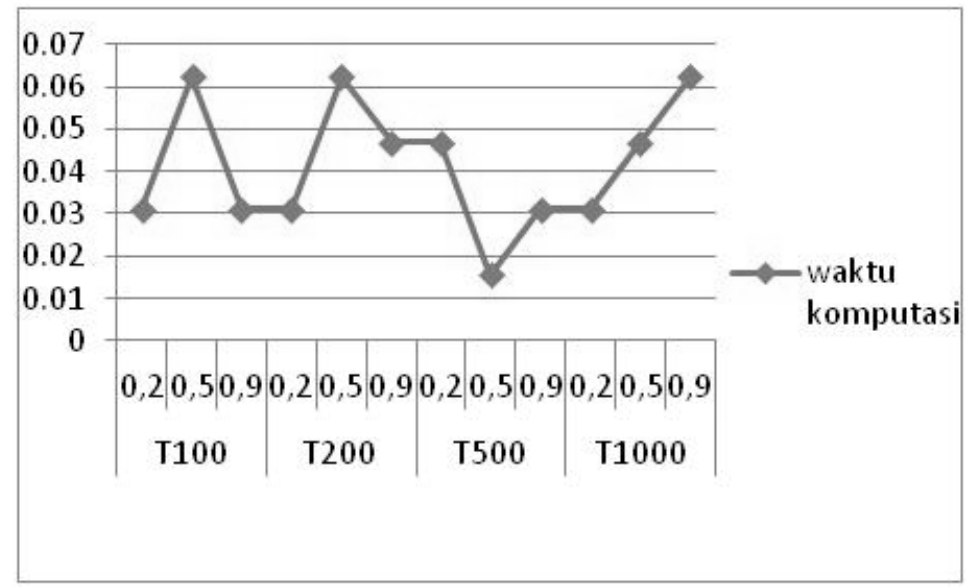

Gambar 8. Grafik perbandingan nilai T dan waktu komputasi

Pada suhu (T) dengan peningkatan fp maka waktu komputasi yang dihasilkan cenderung lebih besar meskipun masih ada yang dalam peningkatan fp tersebut waktu komputasinya tetap. Begitu juga pada peningkatan suhu (T) waktu komputasi yang dihasilkan juga semakin banyak meskipun juga ada salah satu yang tetap tapi keseluruhan cenderung waktu komputasinya naik. Hal ini dikarenakan pembangkitan dari bilangan random untuk penggunaan aturan pengacakan juga berpengaruh karena jika pengacakan semakin sulit maka akan dibutuhkan waktu yang lama.

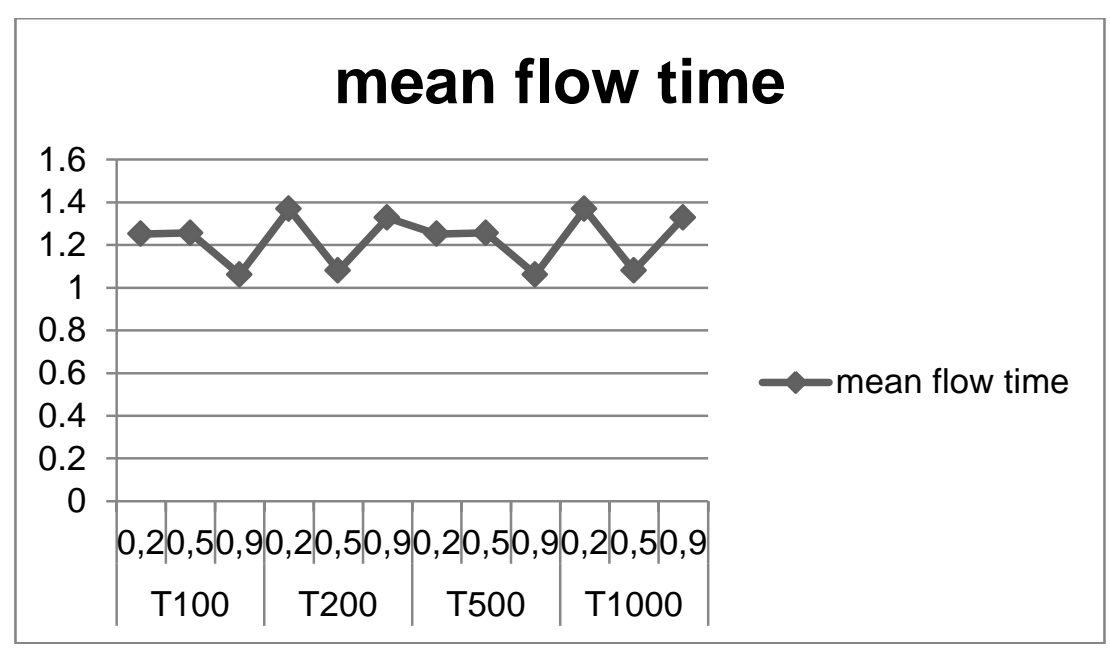

Gambar 9. Grafik Perbandingan nilai T dan mean flowtime

Pada grafik diatas untuk suhu (T) 100 dengan menggunakan fp 0.2 menghasilkan mean flow time 1.2519 detik. Hal ini dikarenakan penurunan suhu yang sangat cepat dan proses pencarian solusi juga akan cepat selesai. Untuk T 100 dengan menggunakan fp 0.5 menghasilkan mean flow time yang lebih besar yaitu 1.256 detik. Pada T 100 dengan menggunakan fp 0.9 didapat mean flow time yang lebih rendah dari fp sebelumnya yaitu 1.061 detik, karena pencarian solusi juga semakin banyak, oleh karena itu setiap faktor penurunan/pereduksi suhu (fp) yang digunakan juga mempengaruhi waktu komputasi yang dihasilkan. 


\section{Perbandingan Penjadwalan Perusahaan Dengan Penjadwalan Simulated Annealing (SA)}

Tabel 1. Perbandingan Penjadwalan Perusahaan Dengan Penjadwalan Simulated Annealing (SA)

\begin{tabular}{|c|c|c|c|}
\hline \multicolumn{4}{|c|}{ Perbandingan Metode Usulan SA Dengan Perusahaan } \\
\hline NO. & Parameter & Usulan Schedule SA & Schedule Perusahaan \\
\hline 1 & $\begin{array}{l}\text { Urutan } \\
\text { optimal }\end{array}$ & $\begin{array}{l}O_{712}, O_{723}, O_{313}, O_{322}, O_{414} \\
O_{212}, O_{515}, O_{334}, O_{111}, O_{341} \\
O_{611}, O_{122}, O_{133}, O_{425}, O_{524} \\
O_{735}, O_{744}, O_{623}, O_{433}, O_{532} \\
O_{634}, O_{144}, O_{221}, O_{155}, O_{541} \\
O_{751}, O_{645}, O_{234}, O_{442}, O_{553} \\
O_{355}, O_{245}, O_{652}, O_{451}, O_{253,}\end{array}$ & $\begin{array}{c}O_{712}, O_{515}, O_{723}, O_{735}, O_{212} \\
O_{111}, O_{414}, O_{313}, O_{611}, O_{744}, \\
O_{221}, O_{623}, O_{425}, O_{322}, O_{234}, \\
O_{122}, O_{634}, O_{524}, O_{532}, O_{751} \\
O_{645}, O_{652}, O_{433}, O_{334}, O_{133} \\
O_{541}, O_{144}, O_{155}, O_{442}, O_{553}, \\
O_{341}, O_{245}, O_{451}, O_{253}, O_{355}\end{array}$ \\
\hline 2 & Total Biaya Produksi & \multicolumn{2}{|c|}{ Rp. 662.380.290/menit $\quad$ Rp.856.189.620/menit } \\
\hline 3 & Makespan & 1391 menit & 1506 menit \\
\hline 4 & Selisih waktu & \multicolumn{2}{|c|}{407 menit } \\
\hline 5 & Efisiensi makespan & \multicolumn{2}{|c|}{$22,64 \%$} \\
\hline 6 & $\begin{array}{l}\text { Rata-rata Efisiensi idle } \\
\text { time }\end{array}$ & \multicolumn{2}{|c|}{$33.91 \%$} \\
\hline
\end{tabular}

Metode SA menunjukkan lebih efisien 22,64 \% dibanding dengan metode yang diterapkan oleh perusahaan saat ini berdasarkan nilai makespannya. Selain itu untuk rata-rata efisiensi idle time, metode SA menunjukkan lebih efisien $33.91 \%$ dibanding dengan metode yang diterapkan oleh perusahaan saat ini.

\section{KESIMPULAN}

Penjadwalan produksi dengan metode Simulated Annealing (SA) dari analisa pada pembahasan sebelumnya didapat solusi pada parameter suhu (T) 1000 dan parameter faktor penurunan suhu (fp) 0.5 menghasilkan makespan sebesar 1391 menit $\approx 23$ jam, dengan urutan penjadwalannya : $O_{712}, O_{723}, O_{313}, O_{322}, O_{414}, O_{212}, O_{515}, O_{334}, O_{111}, O_{341}, O_{611}$, $O_{122}, O_{133}, O_{425}, O_{524}, O_{735}, O_{744}, O_{623}, O_{433}, O_{532}, O_{634}, O_{144}, O_{221}, O_{155}, O_{541}, O_{751}, O_{645}$, $O_{234}, O_{442}, O_{553}, O_{355}, O_{245}, O_{652}, \square_{451}, \square_{253}$, dimana urutan pengerjaan produksinya mulai dari Kusen pintu kamar mandi (job 7), daun jendela (job3), daun pintu kamar (job4), kusen jendela (job2), daun pintu utama (job5), kusen pintu utama (job1), daun Pintu kamar mandi (job6).

Dari hasil perbandingan pada pembahasan sebelumnya penjadwalan yang dilakukan oleh perusahaan menghasilkan makespan sebesar 1506 menit $\approx 25$ jam dan penjadwalan dengan metode SA menghasilkan makespan sebesar 1391 menit $\approx 23$ jam. Maka hasil makespan penjadwalan dengan metode SA lebih baik dengan selisih waktu 2 jam. Selain makespan juga didapat rata-rata idle time dari metode SA lebih baik yaitu 33,91\% pada tiap mesin.

\section{DAFTAR PUSTAKA}

[1] Suyanto.(2010). Algoritma Optimasi Deterministik atau Probabilitik (hal. 115). Yogyakarta: Graha Ilmu.

[2] Ginting, Rosnani. (2009). Penjadwalan Mesin (hal.4). Yogyakarta : Graha Ilmu.

[3] Santosa dan Willy, (2011). Metoda Metaheuristik konsep dan implementasi (hal. 226 228). Surabaya: Guna Widya. 
[4] Damanik, Dian Amru. Skripsi, 2011. "Penjadwalan Produksi dengan metode Simulated Annealing Pada Unit Produksi Daun Pintu di PT. Mahogany Lestari”. Fakultas Teknik, Universitas Sumatera Utara. Medan.

[5] Firdaus Muhammad. (2014), Penjadwalan produksi flow shop dengan metode simulate Annealing. Skripsi jurusan Teknik Industri, fakultas TEKNIK Universitas Muhammadiyah Malang. 